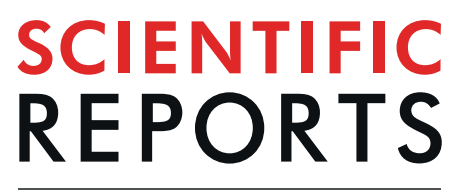

\title{
The effectiveness of disinfectant and steam exposure treatments to prevent the spread of the highly invasive killer shrimp, Dikerogammarus villosus
}

\author{
Stephanie J. Bradbeer ${ }^{1,9}$, Neil E. Coughlan ${ }^{2,3,4,9}$, Ross N. Cuthbert ${ }^{2,3}$, Kate Crane ${ }^{2,3}$, \\ Jaimie T. A. Dick, ${ }^{2}$, Joe M. Caffrey ${ }^{5}$, Frances E. Lucy ${ }^{4}$, Trevor Renals ${ }^{6}$, Eithne Davis ${ }^{4}$, \\ Daniel A. Warren ${ }^{1,8}$, Benjamin Pile ${ }^{1}$, Claire Quinn ${ }^{7}$ \& Alison M. Dunn ${ }^{1,8^{*}}$
}

Biosecurity protocols designed to prevent the spread of invasive alien species (IAS) are now an essential aspect of IAS management. However, the effectiveness of various biosecurity treatments requires further exploration. Killer shrimp, Dikerogammarus villosus, a notoriously high impact and ecosystem destabilising invader, has rapidly spread across Europe, and is of concern to invade Northern America. In this study, we examine the effectiveness of three commonly used, broad-spectrum disinfectants to cause mortality of $D$. villosus: Virasure Aquatic, Virkon Aquatic, and Virkon S. Immersion and spray treatments of $1 \%, 2 \%$ and $4 \%$ disinfectant solutions were examined for applications of up to 300 secs immersion and for up to ten consecutive sprays. Furthermore, we assessed the effectiveness of steam $\left(\geq 100^{\circ} \mathrm{C}\right)$ treatments for up to 120 secs. For all disinfectants, immersion in $1 \%$ solutions caused $100 \%$ mortality at $\geq 120$ secs. At higher concentrations, shorter immersion times caused complete mortality: 60 and 15 secs for $2 \%$ and $4 \%$ solutions, respectively. Five sprays of $2 \%$ and $4 \%$ solutions resulted in $100 \%$ mortality, for all disinfectants. Direct steam exposure was highly effective, with complete $D$. villosus mortality occurring at $\geq 10$ secs. Overall, brief exposure to broad-spectrum disinfectants and direct steam could be used to limit $D$. villosus spread.

Biological invasions of invasive alien species (IAS) are a major driver of biodiversity loss, and detrimentally affect the structuring, functioning, economic and social value of ecosystems worldwide ${ }^{1,2}$. In an age of rapid globalisation, the anthropogenic platforms that facilitate the accidental spread of IAS are well documented and the rate of biological invasions has increased in recent years ${ }^{3}$. Invasive alien species, synonymously termed invasive non-native species are species present outside of their native range with associated adverse impacts ${ }^{4}$. Given the multiple dispersal pathways and array of vectors ${ }^{5-8}$, freshwater ecosystems in particular are considered to be especially vulnerable to the introduction and further spread of IAS ${ }^{2,9,10}$. There is a wide range of users' that access and work in the freshwater environment, all of which can present a risk of spreading IAS from one location to another. Management options for effective and efficient control and eradication of established IAS populations are often complex, expensive, resource-intensive, and can be damaging to non-target species ${ }^{10,11}$. Therefore, prevention of the introduction and secondary spread of IAS is the first line of defence. Biosecurity is the collectively term

\footnotetext{
${ }^{1}$ School of Biology, Faculty of Biological Sciences, University of Leeds, Leeds, LS2 9JT, UK. ${ }^{2}$ Institute for Global Food Security, School of Biological Sciences, Queen's University Belfast, 19 Chlorine Gardens, Belfast, BT9 5DL, Northern Ireland, UK. ${ }^{3}$ Queen's Marine Laboratory, Queen's University Belfast, $12-13$ The Strand, Portaferry, BT22 1PF, Northern Ireland, UK. ${ }^{4}$ Centre for Environmental Research, Innovation \& Sustainability, Institute of Technology

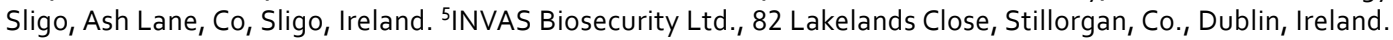
${ }^{6}$ Environment Agency, Sir John Moore House, Victoria Square, Bodmin, Cornwall, PL31 1EB, UK. ${ }^{7}$ School of Earth \& Environment, University of Leeds, Leeds, LS2 9JT, UK. ${ }^{8}$ Water@leeds, School of Geography, University of Leeds, Leeds, LS2 9JT, UK. ${ }^{9}$ These authors contributed equally: Stephanie J. Bradbeer and Neil E. Coughlan. *email: a.dunn@leeds.ac.uk
} 
for actions taken to decontaminate equipment and thus aims to prevent the spread of IAS and has become a key aspect of IAS management strategies ${ }^{12-14}$. Accordingly, there is an urgent need to enhance biosecurity by identifying simple prevention protocols that minimise risk of spread yet remain user and environmentally friendly ${ }^{13,15-18}$.

Aquatic disinfectants such as Virasure Aquatic, Virkon S and Virkon Aquatic are used by recreational water users and responsible authorities, including government agencies, for the decontamination of equipment. These disinfectants are available in powder or tablet form and can be applied through spray applications or immersion of the equipment into disinfectant solutions. Although broad-spectrum aquatic disinfectants have been demonstrated to kill harmful pathogenic microbes and various invasive Mollusca species ${ }^{19,20}$, the effectiveness of these oxidising agents in killing free-living aquatic IAS requires further study. Recent studies have shown partial effectiveness of disinfectants in killing invasive aquatic plants and invertebrates ${ }^{14,17,18}$. However, identification of optimal disinfectant treatment to achieve complete mortality of a range of IAS, whilst minimising time and expense, including testing several types of disinfectants is still required. Steam exposure has also been proposed as a treatment to decontaminate equipment that may have been exposed to IAS. Short applications of steam have been effective in killing both invasive macrophyte ${ }^{21}$ and invertebrates ${ }^{17,22,23}$, however, further testing is still required to determine efficacy for species-specific treatments. Further, the identification of practical and efficacious biosecurity protocols is essential for the reliable uptake of biosecurity practices by environmental stakeholders and prevent behavioural barriers ${ }^{15}$.

The killer shrimp, Dikerogammarus villosus (Sowinsky 1894), is a highly invasive euryoecious amphipod crustacean native to the Ponto-Caspian region. It has spread and successfully colonised most of the major European inland waterways ${ }^{1}$ having been spread by many anthropogenic vectors ${ }^{5,6}$ and is of concern to invade Northern America. Capable of destabilising ecosystems, D. villosus is an especially damaging invader that causes profound declines of native macroinvertebrate populations ${ }^{1,24}$, and has been found to even prey upon fish eggs and larvae ${ }^{25}$. The propagule pressure associated with $D$. villosus is considered to be high, as one gravid female can to hold up to 190 eggs $^{26}$, therefore introductions of even one organism may result in establishment, as seen in other amphipod species $^{27}$. Accordingly, the need to prevent further potential spread, and therefore reduce propagule pressure of this prolific invader is clear.

In this study, we examined the efficacy of immersion and spraying of selected broad-spectrum disinfectants and direct steam exposure to cause mortality of $D$. villosus. To achieve this we examine the effectiveness of three commonly used disinfectants, including two previously untested disinfectants, Virasure Aquatic and Virkon Aquatic. In addition, we assess the effectiveness of direct steam spray for a range of application durations, including a very short and previously untested duration of 5 secs. Examined exposure times were designed to reflect realistic application times achievable by users of such biosecurity protocols. We hypothesise that greater concentrations and longer exposure times will cause substantial, if not complete mortality of $D$. villosus specimens, reducing potential propagule pressure. Equally, we expect that longer exposures of steam that induce thermal shock, rapidly killing D. villosus.

\section{Results}

Immersion in $\mathbf{1 \%}$ disinfectant solutions. Immersion in $1 \%$ disinfectant caused significant mortality in D. villosus $\left(\chi^{2}=432.32, \mathrm{df}=3, \mathrm{P}<0.001\right)$. Total mortality of $D$. villosus was evidenced following immersion in $1 \%$ of all three disinfectant solutions for $\geq 120$ secs (Table 1). All control groups displayed $0 \%$ mortality. Furthermore, for $1 \%$ solutions, Virasure Aquatic caused significantly higher mortality than either Virkon Aquatic or Virkon $\mathrm{S}$ (both $\mathrm{P}<0.05)$. For example, at 30 secs exposure, Virasure Aquatic resulted in $>70 \%$ mortality compared to $<50 \%$ mortality for both Virkon disinfectants. Exposure time also significantly affected mortality $\left(\chi^{2}=107.71\right.$, $\mathrm{df}=3, \mathrm{P}<0.001$ ), wherein the percentage mortality following immersion of 30 secs was significantly lower than that of longer exposure times (all $\mathrm{P}<0.001)$. There was no significant interaction term $\left(\chi^{2}=9.16, \mathrm{df}=9\right.$, $\mathrm{P}>0.05)$.

Immersion in $\mathbf{2} \%$ or $\mathbf{4} \%$ disinfectant solutions. Following immersion treatments in $2 \%$ and $4 \%$ disinfectant solutions, total $D$. villosus mortality was observed for all disinfectant treatments at exposure durations of $\geq 60$ secs (Table 1 ). A low mean mortality rate of $3.3 \%$ was detected for the control groups. Overall, treatment had a significant effect on $D$. villosus mortality $\left(\chi^{2}=712.59, \mathrm{df}=6, \mathrm{P}<0.001\right)$. Treatment with $2 \%$ Virasure Aquatic was significantly more effective than either $2 \%$ Virkon Aquatic or Virkon S (both $\mathrm{P}<0.001$ ). Furthermore, immersions in all $4 \%$ disinfectant solutions were significantly more efficacious than $2 \%$ disinfection in Virkon Aquatic or Virkon S (all P $<0.001$ ). However, submersion in $2 \%$ Virasure Aquatic did not differ significantly from $4 \%$ Virasure Aquatic or $4 \%$ Virkon Aquatic (both $\mathrm{P}>0.05$ ), whilst 4\% Virkon S was more effective than $2 \%$ Virasure Aquatic $(\mathrm{P}<0.001)$. Immersion in $4 \%$ Virkon $\mathrm{S}$ was significantly more effective in inducing $D$. villosus mortality than $4 \%$ Virkon Aquatic $(\mathrm{P}<0.001)$, yet was more similar to $4 \%$ Virasure Aquatic $(\mathrm{P}>0.05)$. Exposure time significantly affected mortality $\left(\chi^{2}=499.42, \mathrm{df}=4, \mathrm{P}<0.001\right)$, with 5 secs and 15 secs exposures significantly less efficacious than 30 secs, 60 secs or 300 secs exposures overall (all $\mathrm{P}<0.01$ ). There was no significant interaction term $\left(\chi^{2}=16.52, \mathrm{df}=24, \mathrm{P}>0.05\right)$.

Disinfectant spray. Disinfectant spray treatments caused significant mortality of D. villosus $\left(\chi^{2}=247.43\right.$, $\mathrm{df}=9, \mathrm{P}<0.001$ ). A low mean mortality rate of up to $6.6 \%$ was recorded within control groups (Table 1 ). Total D. villosus mortality was observed following treatments of $2 \%$ and $4 \%$ solutions of all three disinfectants after 5 sprays. Five spray treatments of $1 \%$ solutions resulted in high but not complete mortality. The maximum number of sprays tested here, 10 sprays, resulted in a mean mortality of $86.6 \%$ for $1 \%$ Virkon Aquatic and Virkon S and $100 \%$ mortality for $1 \%$ Virasure Aquatic. Treatment with 1\% Virasure Aquatic caused greater mortality rates than either $1 \%$ Virkon Aquatic or $1 \%$ Virkon S solutions (both $\mathrm{P}<0.05$ ), whilst the two Virkon products were more similar $(\mathrm{P}>0.05)$. All $4 \%$ disinfectant treatments caused significantly greater mortality than $1 \%$ Virkon Aquatic 


\begin{tabular}{|c|c|c|c|c|c|c|c|}
\hline \multirow[b]{2}{*}{ Treatment } & \multirow[b]{2}{*}{ Concentration } & \multicolumn{6}{|c|}{ Exposure Time (s) } \\
\hline & & 5 & 15 & 30 & 60 & 120 & 300 \\
\hline \multicolumn{8}{|c|}{ Immersion in $1 \%$ disinfectants } \\
\hline Control & $0 \%$ & - & - & 0 & 0 & 0 & 0 \\
\hline Virasure Aquatic & $1 \%$ & - & - & $83.3 \pm 12$ & $\underline{100}$ & 100 & 100 \\
\hline Virkon Aquatic & $1 \%$ & - & - & $46.6 \pm 3.3$ & $96.3 \pm 3.3$ & $\underline{100}$ & $\underline{100}$ \\
\hline Virkon S & $1 \%$ & - & - & $40 \pm 5.7$ & $86.6 \pm 3.3$ & $\underline{100}$ & $\underline{100}$ \\
\hline \multicolumn{8}{|c|}{ Immersion in $2 \%$ and $4 \%$ disinfectants } \\
\hline Control & $0 \%$ & 0 & 0 & $3.3 \pm 3.3$ & $3.3 \pm 3.3$ & - & 0 \\
\hline \multirow{2}{*}{ Virasure Aquatic } & $2 \%$ & $23.3 \pm 8.8$ & $\underline{100}$ & $\underline{100}$ & $\underline{100}$ & - & $\underline{100}$ \\
\hline & $4 \%$ & $46.6 \pm 8.8$ & $\underline{100}$ & $\underline{100}$ & $\underline{100}$ & - & $\underline{100}$ \\
\hline \multirow{2}{*}{ Virkon Aquatic } & $2 \%$ & $3.3 \pm 3.3$ & $56.7 \pm 12$ & $\underline{100}$ & $\underline{100}$ & - & $\underline{100}$ \\
\hline & $4 \%$ & $23.3 \pm 8.8$ & $\underline{100}$ & $\underline{100}$ & $\underline{100}$ & - & $\underline{100}$ \\
\hline \multirow{4}{*}{ Virkon S } & $2 \%$ & $3.3 \pm 3.3$ & $56.7 \pm 26$ & $86.6 \pm 3.3$ & $\underline{100}$ & - & $\underline{100}$ \\
\hline & $4 \%$ & $80 \pm 15.3$ & $\underline{100}$ & $\underline{100}$ & $\underline{100}$ & - & $\underline{100}$ \\
\hline & & \multicolumn{6}{|c|}{ No. of sprays } \\
\hline & & \multicolumn{2}{|l|}{2} & \multicolumn{2}{|l|}{5} & \multicolumn{2}{|l|}{10} \\
\hline \multicolumn{8}{|l|}{ Disinfectant spray } \\
\hline Control & $0 \%$ & \multicolumn{2}{|l|}{0} & \multicolumn{2}{|l|}{0} & \multicolumn{2}{|l|}{$6.6 \pm 6.6$} \\
\hline \multirow{3}{*}{ Virasure Aquatic } & $1 \%$ & \multicolumn{2}{|l|}{$66.6 \pm 24$} & \multicolumn{2}{|l|}{$80 \pm 20$} & \multicolumn{2}{|l|}{$\underline{100}$} \\
\hline & $2 \%$ & \multicolumn{2}{|l|}{$20 \pm 11.5$} & \multicolumn{2}{|l|}{$\underline{100}$} & \multicolumn{2}{|l|}{$\underline{100}$} \\
\hline & $4 \%$ & \multicolumn{2}{|l|}{$\underline{100}$} & \multicolumn{2}{|l|}{$\underline{100}$} & \multicolumn{2}{|l|}{$\underline{100}$} \\
\hline \multirow{3}{*}{ Virkon Aquatic } & $1 \%$ & \multicolumn{2}{|l|}{$20 \pm 11.5$} & \multicolumn{2}{|l|}{$66.6 \pm 13.3$} & $86.6 \pm 13.3$ & \\
\hline & $2 \%$ & $13.3 \pm 13.3$ & & $\underline{100}$ & & $\underline{100}$ & \\
\hline & $4 \%$ & $80 \pm 20$ & & $\underline{100}$ & & $\underline{100}$ & \\
\hline & $1 \%$ & $6.6 \pm 6.6$ & & $73.3 \pm 13.3$ & & $86.6 \pm 6.6$ & \\
\hline Virkon S & $2 \%$ & $33.3 \pm 13.3$ & & $\underline{100}$ & & $\underline{100}$ & \\
\hline & $4 \%$ & 100 & & $\underline{100}$ & & 100 & \\
\hline & & Exposure $\mathrm{T}$ & me (s) & & & & \\
\hline & & Control & 5 & 10 & 30 & 60 & 120 \\
\hline Steam spray & & & & & & & \\
\hline Steam $\geq 100^{\circ} \mathrm{C}$ & - & 0 & $70 \pm 25.2$ & $\underline{100}$ & $\underline{100}$ & $\underline{100}$ & $\underline{100}$ \\
\hline
\end{tabular}

Table 1. Mean $( \pm \mathrm{SE})$ raw percentage mortality of Dikerogammarus villosus at $24 \mathrm{hr}$ following exposure to disinfectant and steam treatments. All treatments were replicated three times. Underlined and bold region delineates complete mortality.

or $1 \%$ Virkon S solutions (all $\mathrm{P}<0.01$ ), but were more similar to $1 \%$ Virasure Aquatic (all $\mathrm{P}>0.05$ ). Treatments with $2 \%$ disinfectants were similar among products (all $\mathrm{P}>0.05$ ). Increased quantity of sprays also significantly influenced mortality $\left(\chi^{2}=140.99, \mathrm{df}=2, \mathrm{P}<0.001\right)$, with mortality following 2 sprays being significantly lower than treatment with 5 or 10 sprays, at all concentrations (all $\mathrm{P}<0.001$ ). There was no significant interaction term between spray treatment and exposure $\left(\chi^{2}=5.83, \mathrm{df}=18, \mathrm{P}>0.05\right)$.

Steam spray. Total D. villosus mortality was caused by direct steam exposures of $\geq 10$ secs, whilst exposure for 5 secs resulted in mean $70 \%$ mortality (Table 1). All control groups displayed $0 \%$ mortality. Steam treatments had a significant effect on mortality of $D$. villosus $\left(\chi^{2}=148.13, \mathrm{df}=5, \mathrm{P}<0.001\right)$. There were no significant differences in mortality among steam application durations (all $\mathrm{P}>0.05)$.

\section{Discussion}

Immersion in disinfectant solutions was shown to be a suitable potential biosecurity treatment leading to complete D. villosus mortality. Mortality was greater at higher concentrations of disinfectant and for longer immersion durations. For all three disinfectants tested, total mortality of $D$. villosus was achieved following immersion times of $\geq 120$ secs, 60 secs and 15 secs for $1 \%, 2 \%$ and $4 \%$ solutions, respectively. Disinfectant spray treatments were also effective. Total D. villosus mortality was observed for all three disinfectants at $2 \%$ and $4 \%$ solutions following 5 spray treatments. High mortality ( $>85 \%$ ) was recorded following 10 spray treatments of $1 \%$ solutions. Overall, for shorter immersion times and reduced spray exposure, Virasure Aquatic solutions appeared to be marginally more effective than Virkon S and Virkon Aquatic. Steam exposure was highly efficacious, with complete mortality occurring at exposure durations of $\geq 10$ secs and high mortality (70\%) at 5 secs exposure.

Dikerogammarus villosus can adhere and remain attached to water users' equipment ${ }^{28}$, upon which they are capable of surviving for up to 16 days in damp conditions ${ }^{12}$. To inhibit the further overland spread of this highly invasive amphipod, biosecurity practices utilising disinfectant treatments would be especially beneficial for decontamination of small items of PPE and equipment. For instance, wetsuits, waders and nets could be 
completely immersed in disinfection baths, while spray applications may be more suitable for the decontamination of larger equipment, e.g. boats, outboard motors, and vehicles ${ }^{21,29}$. Furthermore, water intake-systems, designed to aid cooling of outboard motors, or large pipes such as those used in flood management and raw water movement could also be flushed with disinfectant solutions.

Whilst disinfectants have been shown to be effective against microbes and certain IAS ${ }^{18-20}$, evidence presented in the literature does indicate limited effectiveness against other IAS (e.g. macrophytes ${ }^{16,17}$ ). Our findings are in accordance with Sebire et al. (2018) who found $100 \%$ mortality of D. villosus after immersion in $1 \%$ Virkon S for $15 \mathrm{mins}^{18}$. Previous research has identified treatment time as a barrier to good biosecurity practice ${ }^{15}$. We demonstrate that complete mortality can be achieved with shorter treatment durations ( $\geq 120$ secs) using $1 \%$ disinfectant solutions, making this treatment potentially a useful addition to field biosecurity measures. Furthermore, we demonstrate that other disinfectants are also equally as effective as Virkon S, with equal application times of $1 \%$ solutions needed to achieve complete mortality of D. villosus.

We also found that short duration exposure to steam was effective against $D$. villosus, identifying 10 second exposure of steam resulting in complete mortality, in line with findings by Stebbing and Rimmer $(2013)^{22}$. Direct application of pressurised jets of steam may prove to be highly beneficial, particularly when combined with additional cleaning methods such as hand removal, brushing or scraping ${ }^{21,30}$. Equally, steam treatments may aid decontamination of equipment items that are problematic to manually clean, such as niche areas or large complex structures like chain lockers, intake grates, pipework, trailers and vehicles. Whilst the effectiveness of steam to kill a number of IAS has been tested ${ }^{21,23,31}$, the application of steam needs to be tested against a wider range of IAS. Furthermore, considering the apparent effectiveness of thermal shock, pressurised hot water sprays should also be assessed in future studies against a range of IAS, including previously untested macrophytes ${ }^{32,33}$.

The provision of in-field biosecurity stations for a range of stakeholders could act as a suitable mechanism to limit IAS spread ${ }^{15,21,31,34}$. Installation of decontamination apparatus and facilities, with clear guidance, may facilitate utilisation of these simple but highly efficacious biosecurity techniques ${ }^{13,34}$. The provisioning of these biosecurity stations will also create a platform for raising awareness of IAS and biosecurity with all users. These biosecurity facilities could be placed at points of exit and entry (e.g. angling stations and boat ramps) to ensure ease of access to the steam cleaners or large soaking stations containing disinfectants ${ }^{21,23,31}$. Maintenance and responsibility of such stations would be essential, especially in the case of disinfectants, as the disinfectant solutions decay over time and become less effective. Furthermore, suitable disposal methods would need to be in place, such as interceptors for treatment water/disinfectant run-off, especially when considering equipment being cleaned prior to entering a site. Although the risk of toxicity to non-target aquatic organisms through disinfectant residues and spills is considered to be low $^{19}$, further examination of low concentration lethality on non-target species is needed. This is of particular importance at biosecurity stations locations where there is a greater opportunity for repeated spills compared to a single-visited area. Biosecurity guidance must highlight the correct disposal of used disinfectant water. Furthermore, the legal issues concerning the use of broad-spectrum disinfectants as biosecurity agents for invasive macroscopic organisms will need to be addressed (e.g. herbicide or insecticide ${ }^{16,18}$ ).

The results presented here demonstrate that broad-spectrum disinfectants and direct steam applications could be used as part of effective and efficient biosecurity protocols to prevent the further anthropogenic-mediated spread of D. villosus. Reducing the propagule pressure of this prolific invader is essential. Accordingly, promotion and adoption of these techniques by biosecurity campaigns, stakeholder groups, and practitioners should be encouraged. Furthermore, the requirement to perform and adhere to a biosecurity standard should be incorporated into relevant Codes of Practice, with subsequent enforcement in relation to all water users.

\section{Methods}

Specimen collection and maintenance. Dikerogammarus villosus specimens were collected from Grafham Water, Cambridgeshire, UK $\left(52^{\circ} 17^{\prime} 31.2^{\prime \prime} \mathrm{N}, 0^{\circ} 19^{\prime} 23.9^{\prime \prime} \mathrm{W}\right)$ and Cardiff Bay $\left(51^{\circ} 27^{\prime} 14.7^{\prime \prime} \mathrm{N}, 3^{\circ} 09^{\prime} 50.4^{\prime \prime} \mathrm{W}\right)$. Specimens were transported in source water to the University of Leeds, UK and housed in aerated aquaria filled with dechlorinated tap-water, at a constant temperature of $14^{\circ} \mathrm{C}$ under a $12: 12 \mathrm{hr}$ light-dark regime. Organisms were acclimated for over one week prior to experimental use. Adult specimens were used as they have been shown to be less susceptible to treatments than juveniles ${ }^{18}$. Specimens from Cardiff Bay were only used for the assessment of Virkon S disinfectant spray treatments, due to a shortage of Grafham Water specimens.

Immersion in disinfectant solutions. The efficacy of three commercially available disinfectant products, Virasure Aquatic (Fish Vet Group), Virkon Aquatic and Virkon S (Antec Int. DuPont), was examined using 1\% $\left(10 \mathrm{~g} \mathrm{~L}^{-1}\right), 2 \%\left(20 \mathrm{~g} \mathrm{~L}^{-1}\right)$, or $4 \%\left(40 \mathrm{~g} \mathrm{~L}^{-1}\right)$ disinfectant solutions, and a $0 \%\left(0 \mathrm{~g} \mathrm{~L}^{-1}\right)$ control. For all disinfectants, the concentration recommended for general use against microbes is $1 \%$, and we focused on this in addition to higher concentrations of 2 and $4 \%$. All solutions were made using aerated dechlorinated tap water. Initially, immersion in $1 \%$ disinfectant solutions was assessed for four exposure times: 30 secs; 60 secs; 120 secs; 300 secs ( $n=3$ per experimental group). Following this, immersion in $2 \%$ and $4 \%$ solutions were separately assessed for five exposure times: 5 secs; 15 secs; 30 secs; 60 secs; 300 secs ( $n=3$ per experimental group).

In all cases, groups of ten $D$. villosus were weighed (mean \pm SE individual specimen weight: $115.0 \pm 0.9 \mathrm{mg}$ ) and briefly maintained ( $<30 \mathrm{mins}$ ) in aerated dechlorinated tap water in circular containers (SA, $548 \mathrm{~mm}^{2}$; volume, $1917 \mathrm{~mm}^{3}$ ) prior to experimentation. Only active individuals that responded to a stimuli were selected; specimens that displayed visible parasitism or had recently moulted were not used. Using fine-meshed flat-bottomed sieves (SA, $528 \mathrm{~mm}^{2}$; volume, $1848 \mathrm{~mm}^{3}$ ), treatment groups were immersed in disinfectant solutions for the allotted exposure time. Control groups were likewise immersed in dechlorinated tap water (i.e. $0 \%$ solution) for the same exposure times. Following experimental exposure, the fine-mesh sieves containing the ten $D$. villosus were removed from the experimental solution and re-immersed in dechlorinated tap water for a two-minute period to remove excess disinfectant; this was repeated twice (see Cuthbert et al. ${ }^{17}$ ). Following this washing process, 
specimen groups were returned to $200 \mathrm{ml}$ of aerated dechlorinated tap water in their original containers for a $24 \mathrm{hr}$ recovery period $\left(14^{\circ} \mathrm{C} ; 12: 12 \mathrm{hr}\right.$ light-dark), after which mortality was assessed. Specimens were considered dead if they did not respond to stimuli and did not hold their pereopoda under their body ${ }^{13}$.

Disinfectant spray. Mist-spray applications for all three disinfectants were examined using $1 \%, 2 \%$ or $4 \%$ solutions, and a $0 \%$ control. Groups of five D. villosus were weighed $(107.4 \pm 1.1 \mathrm{mg})$ and briefly maintained in fine-meshed flat-bottomed sieves (SA, $528 \mathrm{~mm}^{2}$; volume, $1848 \mathrm{~mm}^{3}$ ) within a circular container (SA, $548 \mathrm{~mm}^{2}$; volume, $\left.1917 \mathrm{~mm}^{3}\right)$ in dechlorinated tap water $(<30 \mathrm{mins})$. The sieve was removed from the water and, using a hand-held spray bottle, 2, 5 or 10 spray applications of a disinfectant solution were delivered $(n=3$ per experimental group). This were directly applied to treatment groups held within sieves, at a distance of $6-8 \mathrm{~cm}$ from the exit-point of the spray bottle. Application of one spray equated to $0.75 \mathrm{ml}$ of solution per $528 \mathrm{~mm}^{2}$. The sieves containing the experimental specimens were then left air-exposed for a five minutes period $\left(\sim 20^{\circ} \mathrm{C}\right)$, before being re-immersed in dechlorinated tap water for a period of two minute to removed excess disinfectant. This washing process was repeated twice. Following this, specimen groups were returned to $200 \mathrm{ml}$ of aerated dechlorinated tap water and mortality was assessed following a $24 \mathrm{hr}$ recovery period (as above).

Steam spray. Specimens were directly exposed to a continuous jet of steam for 5 secs, 10 secs, 30 secs, 60 secs, and $120 \operatorname{secs}\left(\geq 100^{\circ} \mathrm{C}\right.$; Karcher SC3) ( $n=3$ per experimental group). Groups of ten D. villosus were weighed $(111.5 \pm 2.4 \mathrm{mg})$ and briefly maintained in fine-meshed flat-bottomed sieves (SA, $528 \mathrm{~mm}^{2}$; volume, $\left.1848 \mathrm{~mm}^{3}\right)$ in aerated dechlorinated tap water within a larger container (SA, $548 \mathrm{~mm}^{2}$; volume, $1917 \mathrm{~mm}^{3}$ ) prior to experimentation. Steam was directly applied to groups held within sieves at a distance of $6-8 \mathrm{~cm}$ from the exit-point of the lance, ensuring equal application over the surface area of the sieve. Following exposure, groups were air-exposed for a 10 minute period $\left(20^{\circ} \mathrm{C}\right)$ to allow gradual cooling before being re-immersed in dechlorinated tap water. This was to avoid a second thermal shock occurring if specimens were immediately returned to water after exposure to high temperatures. Control groups were air-exposed for twelve minutes, i.e. the duration of the longest steam exposure and cooling period combined. Mortality was assessed following a $24 \mathrm{hr}$ recovery period (as above).

Statistical analysis. Statistical analyses were performed using R v3.5.1 ${ }^{35}$. Mortality of D. villosus was analysed using generalised linear models (GLMs) assuming a binomial error distribution and logit link. Reduced-bias estimation and inference was used to account for complete separation ${ }^{36}$. Likelihood ratio tests via analysis of deviance were used to obtain effect sizes ${ }^{37}$ and post hoc tests were performed using least-square means with Tukey adjustments to account for multiplicity ${ }^{38}$, with $\alpha \leq 0.05$. First, the effects of immersion in $1 \%$ disinfectant solutions (4 levels: control; 1\% Virasure Aquatic; 1\% Virkon Aquatic; 1\% Virkon S) and exposure time (4 levels: 30 secs; 60 secs; 120 secs; 300 secs) were collectively analysed. Second, the effects of immersion in both $2 \%$ and $4 \%$ disinfectant treatments ( 7 levels: control; 2\%, 4\% Virasure Aquatic; 2\%, 4\% Virkon Aquatic; 2\%, 4\% Virkon S) and exposure time (5 levels: 5 secs; 15 secs; 30 secs; 60 secs; 300 secs) on mortality rates were likewise assessed. In all cases, non-significant terms and interactions were removed stepwise to obtain the minimum adequate model. Similarly, mortality rates following disinfectant spray treatments were examined using GLMs with respect to spray treatment (10 levels: control, 1\%, 2\%, 4\% Virasure Aquatic; 1\%, 2\%, 4\% Virkon Aquatic; 1\%, 2\%, 4\% Virkon S) and exposure time (3 levels: 2 sprays; 5 sprays; 10 sprays). Finally, the mortality rates of $D$. villosus following steam treatments were analysed using a GLM (6 levels: control; 5 secs; 10 secs; 30 secs; 60 secs; 120 secs).

\section{Data availability}

The datasets generated during and analysed during this study are available from the corresponding author on reasonable request.

Received: 20 August 2019; Accepted: 20 December 2019; Published online: 05 February 2020

\section{References}

1. Rewicz, T., Grabowski, M., Macneil, C. \& Karolina, B. The profile of a 'perfect' invader - the case of killer shrimp. Aquat. Invasions 9, 267-288 (2014).

2. Dudgeon, D. et al. Freshwater biodiversity: Importance, threats, status and conservation challenges. Biol. Rev. Camb. Philos. Soc. 81, 163-182 (2006).

3. Zieritz, A. et al. Changes in pathways and vectors of biological invasions in Northwest Europe. Biol. Invasions 19, 269-282 (2017).

4. European Union. EU Regulation No 1143/2014 on the prevention and management of the introduction and spread of invasive alien species. Off. J. Eur. Union 317, 35-55 (2014).

5. De Ventura, L., Weissert, N., Tobias, R., Kopp, K. \& Jokela, J. Identifying target factors for interventions to increase boat cleaning in order to prevent spread of invasive species. Manag. Biol. Invasions 8, 71-84 (2017).

6. Anderson, L. G., White, P. C. L., Stebbing, P. D., Stentiford, G. D. \& Dunn, A. M. Biosecurity and vector behaviour: Evaluating the potential threat posed by anglers and canoeists as pathways for the spread of invasive non-native species and pathogens. PLoS One 9, 1-10 (2014).

7. Anderson, L. G., Rocliffe, S., Haddaway, N. R. \& Dunn, A. M. The role of tourism and recreation in the spread of non-native species: a systematic review and meta-analysis. PLoS One 10, 1-15 (2015).

8. Rothlisberger, J. D., Chadderton, W. L., McNulty, J. \& Lodge, D. M. Aquatic Invasive Species Transport via Trailered Boats: What is Being Moved, Who is Moving it, and What Can Be Done. Fisheries 35, 121-132 (2010).

9. Caffrey, J. M. et al. Tackling Invasive Alien Species in Europe: the top 20 issues. Manag. Biol. Invasions 5, 1-20 (2014).

10. Piria, M. et al. Tackling invasive alien species in Europe II: threats and opportunities until 2020. Manag. Biol. Invasions 8, 273-286 (2017).

11. Booy, O. et al. Risk management to prioritise the eradication of new and emerging invasive non-native species. Biol. Invasions., https://doi.org/10.1007/s10530-017-1451-z (2017). 
12. Anderson, L. G., Dunn, A. M., Rosewarne, P. J. \& Stebbing, P. D. Invaders in hot water: A simple decontamination method to prevent the accidental spread of aquatic invasive non-native species. Biol. Invasions 17, 2287-2297 (2015).

13. Shannon, C., Quinn, C. H., Stebbing, P. D., Hassall, C. \& Dunn, A. M. The practical application of hot water to reduce the introduction and spread of aquatic invasive alien species. Manag. Biol. Invasions 9, 417-423 (2018).

14. Coughlan, N. E., Cuthbert, R. N., Kelly, T. C. \& Jansen, M. A. K. Parched plants: survival and viability of invasive aquatic macrophytes following exposure to various desiccation regimes. Aquat. Bot. 150, 9-15 (2018).

15. Sutcliffe, C., Quinn, C. H., Shannon, C., Glover, A. \& Dunn, A. M. Exploring the attitudes to and uptake of biosecurity practices for invasive non-native species: views amongst stakeholder organisations working in UK natural environments. Biol. Invasions 20, 399-411 (2018).

16. Cuthbert, R. N. et al. A dip or a dab: assessing the efficacy of Virasure Aquatic disinfectant to reduce secondary spread of the invasive curly waterweed Lagarosiphon major. Manag. Biol. Invasions $\mathbf{9}$, (2018).

17. Cuthbert, R. N. et al. Die Hard: impact of aquatic disinfectants on the survival and viability of invasive Elodea nuttallii. Aquat. Bot. 154, 11-17 (2019).

18. Sebire, M., Rimmer, G., Hicks, R., Parker, S. \& Stebbing, P. D. A preliminary investigation into biosecurity treatments to manage the invasive killer shrimp (Dikerogammarus villosus). Manag. Biol. Invasions 9, 101-113 (2018).

19. Stockton-Fiti, K. A. \& Moffitt, C. M. Safety and efficacy of Virkon Aquatic as a control tool for invasive Molluscs in aquaculture. Aquaculture 480, 71-76 (2017).

20. Moffitt, C. M., Barenberg, A., Stockton, K. A. \& Watten, B. J. Efficacy of Two Approaches for Disinfecting Surfaces and Water Infested with Quagga Mussel Veligers. Biol. Manag. Invasive Quagga Zebra Mussels West. United States 467-478, https://doi.org/10.1201/b18447-38 (2015).

21. Crane, K. et al. Full steam ahead: direct steam exposure to inhibit spread of invasive aquatic macrophytes. Biol. Invasions 2, (2018).

22. Stebbing, P. \& Rimmer, G. Pressure washer use in the control of aquatic invasive non-native species. Cefas (2013).

23. Joyce, P. W. S. et al. Stay clean: direct steam exposure to manage biofouling risks. Mar. Pollut. Bull. 142, 465-469 (2019).

24. Dick, J. T. A., Platvoet, D. \& Kelly, D. W. Predatory impact of the freshwater invader Dikerogammarus villosus (Crustacea: Amphipoda). Can. J. Fish. Aquat. Sci. 59, 1078-1084 (2002).

25. Taylor, N. G. \& Dunn, A. M. Size matters: predation of fish eggs and larvae by native and invasive amphipods Size matters: predation of fish eggs and larvae by native and invasive amphipods. Biol. Invasions 19, 89-107 (2017).

26. Pöckl, M. Success of the invasive Ponto-caspian amphipod dikerogammarus villosus by life history traits and reproductive capacity. Biol. Invasions 11, 2021-2041 (2009).

27. Wellborn, G. A. \& Capps, E. Establishment of a new population by a single gravid colonist: Implications for Hyalella biogeography and speciation. Evol. Ecol. 27, 101-115 (2013).

28. Bacela-Spychalska, K., Grabowski, M., Rewicz, T., Konopacka, A. \& Wattier, R. The 'killer shrimp' Dikerogammarus villosus (Crustacea, Amphipoda) invading Alpine lakes: overland transport by recreational boats and scuba-diving gear as potential entry vectors? Aquat. Conserv. Mar. Freshw. Ecosyst. 23, 606-618 (2013).

29. Stebbing, P., Sebire, M. \& Lyons, B. Evaluation of a number of treatments to be used as biosecurity measures in controlling the spread of the invasive killer shrimp (Dikerogammarus villosus)-Final report (September 2011). Cefas (2011).

30. Tribou, M. \& Swain, G. Grooming using rotating brushes as a proactive method to control ship hull fouling. Biofouling 31, 309-319 (2015).

31. Coughlan, N. et al. Better biosecurity: spread-prevention of the invasive Asian clam, Corbicula fluminea (Müller, 1774). Manag. Biol. Invasions 10, 111-126 (2019).

32. Morse, J. T. Thermal tolerance, physiologic condition, and population genetics of dreissenid mussels (PhD Diss. Univ. Texas Arlington, Arlingt. Texas, USA (2009).

33. Comeau, S. R. Colonization and decontamination of quagga mussels in the western United States: Monitoring veligers in Lake Mead and field testing in the effects of hot-water spray as a means of watercraft decontamination. Masters Thesis, University of Nevada Las Vegas (2011)

34. Crane, K. et al. Tomorrow Never Dies: biodegradation and subsequent viability of invasive macrophytes following exposure to aquatic disinfectants. Manag. Bio. Invasions. In Review, (2019).

35. Team, R. C. D. R: a language and environment for statistical computing. https://doi.org/10.1002/9781118448908

36. Kosmidis, I., Pagui, E. C. K. \& Sartori, N. brglm2: Bias Reduction in Generalized Linear Models. R Package. (2017).

37. Hastie, T. \& Pregibon, D. Generalized Linear Models. In Statistical Models in S eds. Chamber, J. M. \& Hastie,T. J., Wadsworth \& Brookes/Cole. 107-172 (1992).

38. Lenth, R. V. Least-Squares Means: The R Package lsmeans. Journal of Statistical Software. https://doi.org/10.18637/jss.v069.i01 (2019).

\section{Acknowledgements}

S.J.B. gratefully acknowledges support and funding from Natural Environment Research Council, the Environment Agency and South West Water (Grant ref: NE/N008391/1). SJB also wishes to thank Grafham Water and Cardiff Bay Authority for their assistance in specimen collection. N.E.C., J.T.A.D., J.M.C., F.E.L. and E.D. gratefully acknowledge support from the Irish Environmental Protection Agency project "Prevention, control and eradication of invasive alien species" (2015-NC-MS-4). J.T.A.D. also acknowledges funding received from NERC. We graciously thank Dr Matthijs Metsellar at Fish Vet Group for providing Virasure Aquatic.

\section{Author contributions}

N.E.C. proposed the study; N.E.C. and S.J.B. designed the experiments; N.E.C. and S.J.B. conducted the experiments; N.E.C. and R.N.C. performed data analysis; all authors contributed to the interpretation of results and the writing of the manuscript, which was led by S.J.B. and N.E.C.

\section{Competing interests}

The authors declare no competing interests.

\section{Additional information}

Correspondence and requests for materials should be addressed to A.M.D.

Reprints and permissions information is available at www.nature.com/reprints.

Publisher's note Springer Nature remains neutral with regard to jurisdictional claims in published maps and institutional affiliations. 
(c) (i) Open Access This article is licensed under a Creative Commons Attribution 4.0 International License, which permits use, sharing, adaptation, distribution and reproduction in any medium or format, as long as you give appropriate credit to the original author(s) and the source, provide a link to the Creative Commons license, and indicate if changes were made. The images or other third party material in this article are included in the article's Creative Commons license, unless indicated otherwise in a credit line to the material. If material is not included in the article's Creative Commons license and your intended use is not permitted by statutory regulation or exceeds the permitted use, you will need to obtain permission directly from the copyright holder. To view a copy of this license, visit http://creativecommons.org/licenses/by/4.0/.

(C) The Author(s) 2020 